\title{
Administração pública brasileira no século 21: seis grandes desafios
}

\author{
Ricardo Luiz Pereira Bueno \\ Universidade Federal de São Paulo (Unifesp) \\ Gabriela de Brelàz \\ Universidade Federal de São Paulo (Unifesp)
}

Natasha Schmitt Caccia Salinas

Universidade Federal de São Paulo (Unifesp)

Elencar os principais desafios enfrentados pela administração pública brasileira no século 21 é, por si só, uma tarefa complexa. Neste artigo, escolhemos seis desafios que julgamos centrais para o Estado brasileiro, suas limitações e também suas potencialidades. Observam-se diversas iniciativas e redes de pesquisa transnacionais atuando nos temas aqui discutidos. Este artigo discute a importância do governo aberto, do combate à corrupção e da corrupção institucional, do desenho institucional da parceria entre Estado e organizações privadas, do uso da big data como espaço para co-produção de serviços públicos baseados em conhecimento, da proposta de compartilhamento de serviços administrativos e de apoio como meio para redução de custos e do processo decisório no contexto das organizações públicas. A intenção deste artigo é colaborar com essas ideias para fomentar futuras discussões no campo, contribuindo assim para seu aprofundamento e desenvolvimento em várias direções.

Palavras-chave: transparência governamental, participação social, corrupção, governo eletrônico, prestação de serviços, parceria institucional, tomada de decisão, administração pública

[Artigo recebido em 3 de junho de 2015. Aprovado em 8 de julho de 2016.] 


\section{Administración pública brasileña en el siglo 21: seis grandes desafíos}

Listar los principales desafíos que enfrenta la administración pública brasileña en el siglo 21 es una tarea compleja. En este texto, elegimos seis desafíos que consideramos fundamentales para el Estado brasileño. Existen varias iniciativas y redes de investigación transnacionales trabajando sobre los temas aquí discutidos. Discutimos la importancia del gobierno abierto, la lucha contra la corrupción y la corrupción institucional, el diseño institucional de la asociación entre el Estado y organizaciones privadas, el uso de datos como espacio para la coproducción de los servicios públicos basados en el conocimiento, el intercambio de servicios administrativos y de apoyo como un medio para reducir los costes y el proceso de toma de decisiones en el contexto de las organizaciones públicas. En este texto en el que señalamos los seis desafíos de la gestión pública en el siglo 21 , la intención es colaborar con estas ideas para promover debates en el campo, contribuyendo así para su profundización y desarrollo en varias direcciones.

Palabras clave: transparencia gubernamental, participación social, corrupción, gobierno electrónico, prestación de servicios, asociación institucional, toma de decisión, administración pública

\section{Public administration in Brazil in the 21st century: six major challenges}

Listing the main challenges faced by the Brazilian public administration in the 21st century is a complex task. In this article, we chose six challenges that we deem central to the Brazilian State, its challenges and its potentialities. There are various initiatives and transnational research networks working on the topics discussed here. This article discusses the importance of open Government, of fighting corruption and institutional corruption, institutional design of partnerships between the State and private organizations, the use of big data as space for co-production of public knowledge-based services, the proposed sharing of administrative services and support as a means to reduce costs, the decisionmaking process in the context of public organizations. The main object of this article is to collaborate with these ideas to promote further discussions in the field, thereby contributing to its deepening and development in several directions.

Keywords: government transparency, social participation, corruption, e-government, service delivery, institutional partnership, decision-making, public administration 


\section{Introdução}

Após décadas de reforma do Estado, a sociedade brasileira se encontra novamente frente a uma velha constatação: a de que o aparato burocrático ainda não representa e atende plenamente às demandas de uma sociedade em contínua transformação. Percebe-se que o movimento gerencial proposto no âmbito da Nova Gestão Pública (NGP), iniciado nos anos 1990, que ressaltou o foco no cidadão, a ênfase na administração gerencial, a valorização do planejamento estratégico, assim como a introdução de mecanismos de mercado, foi progressivamente sendo substituído pela noção de gestão pública participativa, que ainda possui um grande caminho a percorrer.

Elencar os principais desafios enfrentados pela administração pública brasileira no século 21 é, por si só, uma tarefa complexa. Neste texto, escolhemos seis desafios que não minimizam os inúmeros demais, no entanto refletem pontos centrais e importantes de análise e de reflexão sobre o atual Estado brasileiro, suas limitações e também suas potencialidades. São eles: a promoção de um governo aberto, o combate à corrupção, o desafio das parcerias, a prestação de serviços baseada em conhecimento, o compartilhamento dos serviços de apoio e o processo de tomada de decisão. Entendemos que a busca de soluções para esses desafios pautará, por anos vindouros, o trabalho daqueles que estudam e atuam na administração pública brasileira. Esses desafios são descritos a seguir.

\section{Promoção de um governo aberto}

A participação da sociedade civil em diferentes espaços e por meio de diversos mecanismos é um tema amplamente discutido como forma de aprofundar a democracia, ao trazer os cidadãos para a discussão dos diversos problemas que atingem as cidades, as possíveis soluções e a forma como tais soluções se traduzem em políticas públicas (TATAgIBA, 2002, 2004; TeIXeIRA, 2000; LÜCHMANN, 2007; AVRITZER, 2002, 2003, 2009; SANCHEZ, 2004; WAMPLER, 2007; LAVALLE; HOUTZAgER; CASTELLO, 2006).

Recentemente, novos estudos surgem para entender a qualidade da participação, as relações entre os atores envolvidos e a accountability da sociedade civil que participa (DAgNINO; TATAGIBA, 2007; LAVALLE, 2011), assim como para analisar as mudanças ocorridas na participação social com as novas "TICs", assim chamadas as tecnologias de informação e comunicação (MAIA; DINIZ, 2012).

Os espaços e arranjos participativos surgem, com grande ênfase, com a Constituição de 1988. Resultado de um intenso período de redemocratização, ela pontuou claramente o papel dos cidadãos dentro de um contexto democrático, 
sendo, por isso, chamada de Constituição Cidadã. As Constituições Estaduais e as Leis Orgânicas dos Municípios, posteriormente, em todo o Brasil, incorporaram vários preceitos estabelecidos pela Constituição Federal, o que levou essas inovações para o âmbito das cidades. Podemos citar diversos espaços e mecanismos de participação como, por exemplo, conselhos de políticas públicas, orçamentos participativos (OP), comissões de legislação participativa, conferências, audiências públicas, entre outros.

Autores como Dagnino (2002, 2007), Nobre (2004), Elster (1998), Pateman (1970), Young (2006) e Luchmann (2007) discutem a importância da participação popular dentro de um contexto de democracia participativa, que ressalta o papel da participação da sociedade civil na discussão de assuntos que a afetam diretamente e como forma de controle social. Trata-se de atores que atuam individualmente ou como representantes de determinados grupos e interesses da população, discutindo problemas públicos e suas possíveis soluções e participando na formulação, implementação e avaliação de políticas públicas. Os defensores da democracia participativa, de acordo com Dagnino (2011), defendem que a sociedade civil se engaje em um papel de ativismo político, e as visões mais radicais dentro da corrente defendem que a sociedade não se limite a apenas influenciar aqueles que estão no poder, mas que a sociedade deve também participar do processo de tomada de decisão junto ao Estado.

É fundamental entender como esses novos instrumentos se relacionam e quais os resultados alcançados nas últimas décadas. As novas TICs têm muito a contribuir, pois permitem aos cidadãos participar de discussões de que, por motivos de tempo, espaço e recursos financeiros, não conseguem normalmente participar, aproximando, dessa forma, cidadãos do processo de tomada de decisão.

Governo eletrônico, e-gov, e-democracia, e-participação, e-governança são diferentes denominações para uma série de iniciativas que envolvem o uso de TICs na relação entre Estado e cidadãos, e que a estão transformando (PINHO, 2011; MAIA, Diniz, 2012; SAMPaIO, MaIA, MARques, 2010). Para Menezes e Fonseca (2005), governo eletrônico consiste na utilização de novas tecnologias de informação e comunicação para prestação de serviços e informações para cidadãos. Ou seja, "e-gov é toda e qualquer interação por meio eletrônico que objetiva fornecer e obter informações, prestar serviços, bem como transacionar bens e serviços à distância, entre governo e cidadãos, e entre governo e empresas" (MENEZES; FonSECA, 2005, p. 335-336). Através do governo-eletrônico, permite-se o acompanhamento dos governos locais pelos cidadãos e a participação em processos decisórios, por intermédio de passos visíveis e transparentes (FUGINI; MAGGIOLINI; PAGAMICI, 2005).

E-governança pode ser dividida em três dimensões: e-administração pública, e-serviços públicos e e-democracia. "A expressão e-democracia refere-se à ampliação 
da prática democrática utilizando as tecnologias de informação e comunicação." Ou seja, trata-se da comunicação do Estado com o cidadão, não somente por meio da accountability, mas na elaboração e controle das políticas públicas. O termo e-democracia contempla o ativismo no exercício pleno da cidadania, não apenas exercício de direitos (CUNHA; MIRANDA, 2013).

Essas definições fazem parte de uma noção maior denominada governo aberto, que vai além de práticas pontuais e desvinculadas para promover uma política pública ampla, que engloba as cidades na sua relação com seus cidadãos. A discussão de "open government" (NOVECK, 2009) é amplamente discutida em diversos países, sendo Estados Unidos e Inglaterra importantes expoentes nesse debate.

A noção de governo aberto tem o papel da transparência como um grande pilar, mas não se restringe a ela. Acesso aos dados públicos sobre gastos do governo e processos administrativos pode fortalecer a capacidade dos cidadãos nas discussões sobre políticas públicas, na fiscalização dos gastos e na atuação dos funcionários públicos, auxiliando os governos a alocarem de forma mais inteligente os recursos públicos.

Em setembro de 2011, o governo brasileiro, junto com mais sete países (Indonésia, México, Noruega, Filipinas, África do Sul, Reino Unido e Estados Unidos), lançaram uma declaração de governo aberto intitulada Open Goverment Partnership (OGP) e comunicaram, por meio de um plano de ação nacional, como cada país atingiria os objetivos do OGP. Trata-se de uma significativa parceria que busca garantir o compromisso dos governos nacionais com a promoção da transparência, o combate à corrupção e o aumento da participação dos cidadãos com a utilização de TICs, tornando os governos mais responsáveis, abertos e eficazes. Hoje fazem parte da parceria 67 países, e o Brasil se encontra em fase de implementação do primeiro plano de ação e de desenvolvimento do segundo plano de ação (OPEN GOVERNMENT PARTNERSHIP, 2015).

Em novembro de 2011, A Lei Federal no 12.527-também conhecida como a Lei de Acesso à Informação (LAI) - garantiu aos cidadãos brasileiros acesso a informações públicas e, dessa forma, os governos tornaram-se obrigados a promover a transparência e acesso a dados que não fossem restritos por motivos de segurança. Essa lei contribui para que seja possível maior controle social, pois permite acesso à informação e tem potencial de fortalecer a accountability que pressupõe a "noção de responsabilidade dos eleitos, de transparência e de fiscalização", podendo ser também entendida como uma prestação de contas pública (ANGELICO, 2015). Como discutido por Abrucio e Loureiro (2004), os cinco instrumentos para a accountability são controle parlamentar, controles judiciais, controles administrativos financeiros exercidos pelos tribunais de contas e auditores, controle dos resultados da 
administração pública e controle da sociedade civil. Em todos esses tipos de controle, a informação é fundamental.

Algumas iniciativas do Governo Aberto que merecem destaque são o Participa. br - plataforma de participação social entre o Governo Federal e a sociedade civil que promove interação, divulgação de conteúdos, fóruns de debates e consultas; a plataforma digital de discussão do Plano Diretor de São Paulo em 2014, chamada Gestão Urbana, que permitiu a construção de uma minuta colaborativa com a sociedade civil; o portal brasileiro de dados aberto - dados.gov.br; o programa São Paulo Aberta - iniciativa de governo aberto do município de São Paulo que tem como objetivo coordenar, promover e integrar as ações de governo aberto da prefeitura com ênfase na transparência, participação social, inovação tecnológica e integridade das políticas públicas, entre outras.

Vale a pena destacar que, "além das perspectivas de governança e de direitos humanos, o acesso à informação pública - e, mais particularmente, uma legislação de acesso - também é visto como um importante mecanismo anticorrupção (ANGElico, 2015). Combate a corrupção é um dos principais desafios elencados neste artigo para a gestão pública no século 21 , como veremos a seguir.

\section{Combate à corrupção}

Sem dúvida, um dos principais problemas que afligem o Estado brasileiro é a corrupção. Trata-se de um problema histórico e cultural e que possui impactos diretos na economia e no desenvolvimento do País.

Todos os estados, sejam benevolentes ou repressivos, controlam a distribuição de benefícios valiosos e a imposição de custos onerosos. A distribuição destes benefícios e custos está geralmente sob o controle de funcionários públicos que possuem poder discricionário. Indivíduos e firmas privadas que querem tratamento favorável estão dispostos a pagar para obtê-lo. Os pagamentos são proibidos se eles são feitos ilegalmente aos funcionários públicos com o objetivo de obter um benefício ou evitar um custo. A corrupção é um sintoma de que algo deu errado na administração do estado (ROSE-ACKERMAN, 2007, p.9).

A população tem se mostrado extremamente descontente e não disposta a aceitar os diferentes escândalos de corrupção dos últimos anos no Brasil (podemos citar o mensalão, mensalão mineiro, máfia da merenda, desvios envolvendo a Petrobrás e grandes empreiteiras, entre outros), pressionando por políticas de combate à corrupção e punição dos envolvidos. Atualmente, o País encontra-se discutindo uma importante reforma, a política, que afeta diretamente esse problema, sendo o financiamento privado de campanha um dos principais pontos da discussão. 
Lessig (2013) convida-nos a pensar sobre a existência da "corrupção institucional". O autor a define como "as consequências de uma influência que ilegitimamente enfraquece a efetividade de uma instituição, principalmente ao enfraquecer a confiança pública na instituição" (LESSIG, 2013, p. 1).

Para melhor compreender o pensamento de Lessig (2013), é importante partir da definição de Thompson (1995) de corrupção individual e corrupção institucional. O autor define a corrupção individual como a descrita anteriormente, ou seja, com o ganho pessoal ou beneficio de um funcionário público em troca da promoção de interesses privados, como, por exemplo, dinheiro, presentes, viagens internacionais, emprego para familiares, entre outros.

Por outro lado, a corrupção institucional é um ganho ou beneficio político obtido por um funcionário público sob condições que, em geral, tendem a promover interesses privados. Por exemplo, podemos citar bens que são utilizados no processo político, como apoio político, contribuições de campanha, publicidade, apoio e endosso político. No caso brasileiro, é sabido que o financiamento de campanha é de extrema importância para as eleições, sendo esse um importante ativo gerador de corrupção institucional.

\section{O desafio das parcerias}

Diversos são os enfoques possíveis para se caracterizar os modos de interação entre o Estado e organizações privadas para o desempenho de tarefas públicas. Um enfoque conhecido é aquele que se baseia nos interesses e preferências tanto do Estado quanto das organizações privadas acerca dos fins e meios das políticas públicas. De acordo com esse modelo, a natureza da relação entre Estado e organizações privadas pode ser complementar, suplementar ou adversarial (YoNG, 2006), ou, utilizando terminologia semelhante, cooperativa, confrontacional, complementar ou cooptativa (NAJAM, 2000).

Há, também, uma outra forma de se caracterizar as relações entre esses atores, que se baseia nos diferentes tipos de financiamento governamental das organizações privadas e as correspondentes formas jurídicas que dela emergem. Por exemplo, o Estado costuma oferecer contribuições a fundo perdido ao setor sem fins lucrativos, as quais podem assumir a forma de auxílios e subvenções. Há também aquelas situações em que o Estado financia atividades de organizações privadas com e sem fins lucrativos, exigindo-se, em contrapartida, que elas desempenhem determinadas tarefas públicas. Essa forma de financiamento é regida pelos aqui amplamente considerados instrumentos de natureza contratual.

É possível verificar um processo evolutivo em que novas formas de interação somaram-se às antigas ao longo do tempo. Tome-se, neste sentido, o exemplo do 
Brasil. Em tempos remotos, o financiamento estatal do setor privado tinha o objetivo primordial de estimular o empreendedorismo social. Nesse arranjo institucional, as organizações eram vistas como meras receptoras de ajuda financeira governamental. Tome-se o exemplo das instituições filantrópicas de assistência social, como as Santas Casas de Misericórdia, que há séculos recebem ajuda governamental. Na medida em que a burocracia estatal se expandiu, consolidou-se a ideia de que o Estado deveria contratar, e não produzir ou desempenhar diretamente, os bens e serviços de que necessitasse para a realização de suas atividades-fim (SALINAS, 2010). Nesse processo, o Estado passou a adquirir tais bens e serviços de entidades privadas, incluindo as sem fins lucrativos. Contratos de fornecimento de bens duráveis e não duráveis, contratos de obras públicas, entre outros, permearam esse estágio intermediário das parcerias. Nas últimas duas décadas do século 20, no entanto, o financiamento governamental das organizações privadas também assumiu uma nova forma: além das atividades de fomento, auxílios a fundo perdido e a contratação de bens e serviços para uso próprio, o Estado passou a delegar autoridade administrativa para execução de serviços públicos, conferindo-lhes um certo protagonismo na formulação e implementação de projetos e programas governamentais. Serviços de saúde, educação, saneamento básico, iluminação, telefonia, dentre vários outros, passam a ser desempenhados por entes privados, livremente ou por meio de certas restrições governamentais, a depender do status jurídico atribuído pela Constituição e leis esparsas ao serviço.

Nesse novo arranjo, o Estado deixa de atuar diretamente na implementação de políticas públicas, cedendo espaço para as organizações privadas prestarem serviços públicos e realizarem projetos e programas governamentais. Em decorrência disso, o Estado se desvencilha também de ter de construir aparato administrativo próprio para a execução desses serviços, projetos e programas. Cabe às organizações privadas empregar a sua expertise e os seus recursos humanos para implementá-los.

Esse processo de transferência de competências implementadoras do Estado para as organizações privadas se dá, além disso, de modo não coercitivo. As organizações podem escolher livremente se querem ou não atuar em parceria com o Estado, bem como escolhem livremente os serviços, projetos e programas governamentais de que querem participar.

Modelos de parcerias nos quais organizações privadas obrigam-se a implementar as políticas e o Estado a fiscalizar gravitam, no Brasil, em torno das normas que regem diversos instrumentos contratuais, notadamente contratos administrativos de concessão, parcerias público-privadas, contratos de gestão, termos de parceria, termos de colaboração e de fomento, entre outros. Esses instrumentos contratuais, que passaram a reger, de forma nem sempre harmoniosa entre si, as parcerias entre Estado e organizações privadas, possuem regimes jurídicos variados. 
Diferentes tipos de serviços demandam distintos modos de relacionamento expectativas, obrigações, direitos e deveres - entre as pessoas que desempenharão essas tarefas e o Estado. Estado e organizações privadas diferem significativamente no modo como se relacionam entre si nas diversas modalidades de parcerias existentes. Da análise das normas que regem esses relacionamentos, no entanto, nada ou muito pouco se pode dizer acerca do modo como esses atores interagem entre si. Visões normativas, que podem tanto embasar uma menor quanto uma maior presença do Estado na prestação de serviços públicos, muitas vezes não guardam relação com a realidade concreta.

Para tornar claro esse argumento, tome-se o exemplo das parcerias entre Estado e organizações do terceiro setor. Os setores público e privado sem fins lucrativos, ao celebrarem contratos de parceria, possuem recorrentes dificuldades em se adaptar a estilos de gestão e modos de interação social que não lhes são próprios. Essas diferentes racionalidades ou modelos de controle praticados pelo poder público e pelas entidades do terceiro setor terminam por provocar efeitos perversos na gestão dos contratos que esses celebram (SALINAS, 2013). Por um lado, o Estado tenta replicar, nas parcerias que forma, seus modelos de controle administrativo, de caráter formal, hierárquico e rígido. Por outro lado, as entidades do terceiro setor agem pautadas por normas sociais que refletem a cultura de suas comunidades (MASHAW, 2006, p. 118). É comum, por exemplo, verificar uma insatisfação generalizada por parte das entidades do terceiro setor, que terminam por desviar esforços, tempo, recursos e energia - que supostamente deveriam ser empregados na execução material dos projetos - para agir em conformidade com regras rígidas de controle administrativo e burocrático impostas pelo Estado na gestão dos instrumentos contratuais celebrados. Não raras vezes, controles estatais desse tipo, que refletem uma desconfiança do Estado nos mecanismos informais e flexíveis de agir das entidades do terceiro setor, terminam por tolher o potencial criativo e a capacidade de realização das entidades do terceiro setor. Por outro lado, os métodos informais e flexíveis de gestão das entidades do terceiro setor por vezes podem impactar negativamente o processo de implementação das políticas. As entidades do terceiro setor tendem a pautar-se por normas que são eternamente negociáveis, continuamente revistas e frequentemente silenciosas, as quais podem ocasionar problemas como ineficiência e insatisfação do público-alvo das políticas.

Modos particulares de interação entre Estado e organizações privadas com fins lucrativos também são emblemáticos. Tome-se o exemplo da decisão de se delegar para uma organização privada a prestação de um serviço de saneamento básico. Elliott Sclair (2001) observa que essa tomada de decisão deveria implicar, em verdade, a consideração de três fatores que terão impacto na qualidade e nos 
custos dos serviços prestados. Se houver diversos particulares interessados em prestar indiretamente o serviço, e a administração tiver amplo conhecimento sobre o modo como o serviço deve ser prestado, então se torna possível vislumbrar um contrato de concessão que seja altamente favorável para o Estado. No entanto, quando houver apenas uma quantidade mínima de particulares dispostos a prestar em regime de concessão o serviço de saneamento, e a administração não dispuser de conhecimento suficiente acerca da natureza de problemas da prestação do serviço, o contrato que resultará desse contexto tenderá a ser mais vantajoso para o contratado do que para o contratante. Independentemente do nível de competição que existir durante o processo de contratação, após a assinatura do contrato, o sucesso da prestação do serviço dependerá de dois fatores críticos: os limites tecnológicos envolvidos na prestação do serviço e as qualidades interpessoais dos agentes públicos e dos particulares envolvidos no contrato de concessão. Tendo em vista que o serviço de saneamento exige um investimento de capital enorme, tornase inviável, do ponto de vista econômico, a construção de diversas plantas menores de tratamento, as quais possibilitariam um regime de competição na prestação do serviço. Ao contrário, a opção mais econômica será sempre a de construir uma única planta de tratamento de esgoto que venha servir a toda a comunidade. Desse modo, a possibilidade de que haja competição nesse serviço reduz-se praticamente a zero. Além disso, dados os altos custos de transação da operação, a possibilidade de que haja troca de concessionário em um médio prazo também se torna proibitivamente cara. Em resumo, a decisão de se delegar a prestação do serviço não implicará necessariamente economia de recursos para o Estado e para a população. O sucesso da prestação desse serviço residirá exclusivamente na qualidade do serviço prestado, a qual dependerá, em última instância, do relacionamento que se construirá entre a administração e o concessionário. Entre outros elementos-chave para a garantia da efetividade na prestação desse serviço, estão a reputação e a expertise técnica do concessionário.

Ao optar por um contrato de concessão, o poder público está, na prática, delegando a gestão propriamente dita do serviço, especialmente naqueles casos em que metas, tarefas e objetivos especificados no contrato possuírem caráter vago e genérico. A falta de uma maior especificidade nas atribuições dos concessionários implica, na prática, que a esses sejam delegadas decisões não só acerca da operacionalização dos serviços, mas também no que diz respeito ao seu conteúdo propriamente dito. Delegações desse tipo, é certo, podem ser minoradas no próprio âmbito do contrato de concessão, quando exigências de maiores especificações contratuais forem respeitadas, mas também podem ser evitadas por meio de outros arranjos institucionais alternativos à celebração do contrato de concessão, tais como a celebração de contratos de serviços-meio. Tomando o exemplo do serviço 
de manutenção de estradas, nada impede que o Estado se valha da contratação de serviços separados e isolados uns dos outros, de modo a exercer um papel mais ativo na coordenação dos mesmos.

Os dois exemplos acima assinalados revelam que não é possível estabelecer, a priori e de modo generalizado, os métodos de gestão mais apropriados para disciplinar as parcerias entre Estado e atores privados. A definição do melhor arranjo institucional dependerá de uma série de fatores, tais como objeto da parceria, conhecimento e informações das partes sobre as tarefas a serem desempenhadas, capacidades, percepções e modos de atuação dos entes parceiros etc. Uma ampla compreensão de diversas formas de interação entre Estado e atores privados, e do correspondente repertório de mecanismos de gestão contratual, será imprescindível para o aprimoramento das parcerias entre Estado e atores privados no Brasil.

\section{Prestação de serviços baseada em conhecimento}

Ben Wiliamson (2014), ao estudar novas formas de provisão, definiu a prestação de serviços baseada em conhecimento como sendo realizada por intermediário transetorial, sendo coproduzida por meio das atividades do tipo faça você mesmo (Do It Yourself) executadas por cidadãos em associação a um algoritmo mecânico de aprendizagem que processa uma imensa base de dados de forma combinada.

A aspiração por uma prestação de serviço público personalizada e baseada em conhecimento no Reino Unido é um protótipo do que os cientistas políticos Margetts e Dunleavy (2013) descrevem como Governança da Era Digital, que coloca a interação homem-máquina em posição central para o governo. Para elas, a Governança da Era Digital incute a entrega de serviços de e-gov no coração do modelo de negócios do governo e inclui atividades como digitalização de interações com os cidadãos; novas formas de automação, usando tecnologias que não necessitam de intervenção humana; e, em parte, envolve que os cidadãos façam mais em direção a uma administração isocrática, ao estilo "faça por você mesmo" (MARGETTS; DUNLEAVY, 2013).

Isso nos colocaria em direção a uma reconfiguração dos serviços públicos para atender às necessidades individuais dos cidadãos de forma específica, um processo de coproduzir e personalizar os serviços públicos que requer conhecimento e informações sobre os usuários do serviço para serem agrupados, monitorados e interpretados pelos prestadores de serviços e, até mesmo, usados como base para a previsão das necessidades futuras (GREK; OZGA, 2010; MEIJER, 2012).

Segundo Wiliamson (2014), a tarefa de personalizar os serviços públicos vislumbrada por essas organizações envolve o uso de software sofisticado e 
algoritmos que podem ser usados para coletar e analisar o big data sobre usuários do serviço, que consiste de informações pessoais e dados comportamentais individuais, a fim de antecipar ou prever vidas futuras, comportamentos e exigências dos cidadãos.

Nessa perspectiva, os usuários do serviço público são entendidos como coprodutores, juntamente com o software de banco de dados de serviços personalizados. Tudo isso é parte de uma mudança na gestão dos serviços públicos para a utilização de novas formas de governança do conhecimento - conhecimento sobre os utilizadores dos serviços e dos cidadãos, de quem foi cobrado para governálos de forma mais eficaz (FENWICK et al., 2014).

Os centros de gerenciamento e controle integrado disponíveis nas cidades do Rio de Janeiro, Porto Alegre e Curitiba são exemplos para provisão de serviços baseados em conhecimento por meio da agregação, processamento de algoritmos genéticos e análise de dados provenientes de inúmeras fontes (e.g., dados sobre mobilidade urbana, ocorrências policiais, situações climáticas adversas, perfil socioeconômico e de saúde), os quais são utilizados para apoiar a gestão de cidades inteligentes, oferecendo soluções e serviços customizados aos cidadãos.

Recentemente, surgiram experiências como a do Pitch Gov SP, promovido pelo Governo do Estado de São Paulo e a Associação Brasileira de Startups, que possibilitou ao estado oferecer novas soluções aos cidadãos com foco em educação, saúde e conveniência ao cidadão. Essa iniciativa permitiu o acesso dos alunos dos cursos de Moda, Beleza e Construção Civil, oferecidos pelo estado no âmbito da Qualificação Profissional do Fundo Social, aos serviços de intermediação de mão de obra da plataforma GetNinjas, fomentando condições para geração de renda.

No eixo saúde, será fomentada, entre outras iniciativas, a plataforma Saúde Controle, que permite aos usuários alimentar e organizar dados históricos médicos, armazenando informações sobre cirurgias, consultas médicas, exames laboratoriais e a utilização de medicamentos. Por meio do uso das informações que são processadas por algoritmos mecânicos e de aprendizagem, será possível acelerar o diagnóstico e o desenvolvimento de terapias personalizadas com emissão de prescrições farmacêuticas, além do envio de informações e notificações sobre agendamento de consultas, exames e procedimentos médicos.

Introduzir o tema da provisão de serviços baseada em conhecimento de forma coproduzida e meios de governança digital personalizada com base na big data foi o objetivo desta seção; mas uma possível indagação surge no horizonte: será que todos os entes federados precisam desenvolver a sua solução de plataforma para serviços de intermediação de mão de obra, para manutenção em nuvem de informações básicas de saúde da população ou, ainda, para o processamento da folha 
de pagamento dos servidores? Quando existir a possibilidade de compartilhamento de plataformas que representem, a um só tempo, super e infraestrutura para prestação de serviços públicos, mesmo que cada um faça a seu modo, ou na forma institucional mais adequada, respeitando sua autonomia e seu contexto específico, cabe analisar o desafio dos serviços compartilhados.

\section{O desafio dos serviços compartilhados}

A existência, contratação e dinâmica de implementação dos acordos de serviços compartilhados tem uma longa história que data da década de 1980 no setor privado. Mais recentemente, o setor público, notadamente na Austrália, EUA, Inglaterra e Canadá, também se voltou para a adoção de serviços compartilhados como um meio de alcançar maior eficiência administrativa.

Segundo Mclvor, McCracken e McHugh (2011), os acordos de serviços compartilhados têm aumentado seu destaque, abrangendo funções tais como finanças e contabilidade, recursos humanos, contratos, tecnologia da informação e gestão de instalações de serviços. Para Bergeron (2003), em geral os serviços compartilhados envolvem consolidar e padronizar tarefas comuns associadas a uma função de negócio em diferentes partes da organização, uma central de serviços única. Então, esses serviços são fornecidos pelo centro de serviços para outras partes da organização, podendo ser internos ou terceirizados. Apesar de muitos dos serviços prestados pelas funções de retaguarda não serem visíveis para os clientes, eles têm um grande impacto na qualidade do serviço, especialmente quando não estão realizando corretamente suas atribuições esperadas.

No Brasil, tem havido pouca discussão e pesquisa sobre os acordos de serviços compartilhados entre o setor público e o privado sem fins lucrativos. A literatura dos Estados Unidos já se dedica há mais de duas décadas ao tema, normalmente enquadrando-o como "serviços de gestão de organizações" ou "gestão de organizações de apoio" para o setor sem fins lucrativos, como um termo substituto para o modelo com fins lucrativos dos "serviços compartilhados de apoio" (ARSENAULt, 1998).

Para Walsh, McGregor-Lowndes e Newton (2006), as discussões no setor sem fins lucrativos, em particular o setor de serviços comunitários, tenderam a concentrarse mais sobre a integração de serviços e a racionalização das vias de cliente por meio do sistema de serviço (GLENDINNING; MEANS, 2004; LEUTZ, 1999; WALDFOGEL, 1997).

Ainda segundo os autores, o ímpeto para explorar os serviços compartilhados advém como resposta às mudanças no ambiente operacional das organizações e à 
constante redução de recursos associada ao incremento das expectativas em relação aos produtos, o que tem feito o setor sem fins lucrativos busca maior eficiência. De outro lado, a legislação e o arcabouço institucional mais amplo têm evoluído no sentido de que a colaboração entre setores público e sem fins lucrativos precisa ser transparente, com ênfase na melhoria dos processos de prestação de contas.

Em geral, as organizações de serviços compartilhados no setor público ou sem fins lucrativos são responsáveis por proverem superestrutura ao setor, fornecendo aconselhamento em atividades como advocacy e planejamento, ou pela infraestrutura de apoio às organizações por meio de atividades de treinamento, apoio nas atividades financeiras e de prestação de contas, compartilhamento de boas práticas, etc.

Em relação à forma organizacional, o arranjo para compartilhamento de atividades pode assumir os seguintes modelos: a) uma organização maior compartilha sua estrutura com as demais e cobra pelo serviço prestado; b) uma organização é criada com a contribuição de várias entidades e dividem o custo; e c) uma nova organização é criada por terceiros com a finalidade de prestar e cobrar pelos serviços prestados.

Figura I - Arranjos de serviços compartilhados

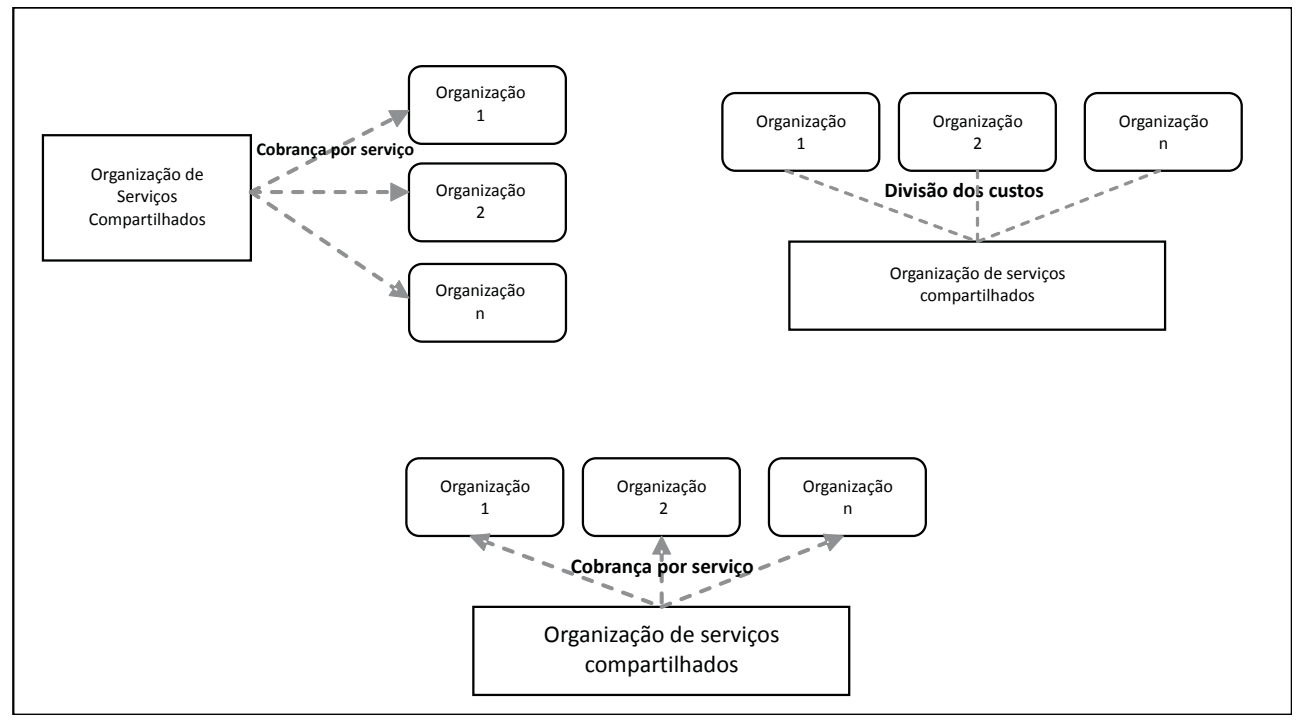

Fonte: Elaboração própria.

É importante frisar que a proposta de compartilhamento de serviços não envolve a centralização das competências e atributos centrais de organizações públicas e não lucrativas; pelo contrário, tem como propósito favorecer a concentração em atividades centrais das entidades, permitindo a entrega de maneira mais eficiente 
em atividades e processos passíveis de padronização entre as diversas entidades participantes do arranjo.

No contexto brasileiro, diversas organizações congêneres poderiam empregar tal arranjo visando a maior eficácia, ao mesmo tempo em que melhorariam sua relação de eficiência. Uma questão que se coloca é saber se essa opção aos gestores não sofreria do mesmo problema das avaliações realizadas no setor público que, ao focalizar com ênfase os objetivos e incentivos relacionados, podem se revelar disfuncionais quando em ambiente característico como o setor público, no qual os objetivos são ambíguos e de definição fluida (BEVAN; HOOD, 2006).

\section{O desafio da tomada de decisão}

A tomada de decisão e o processo decisório são temas relevantes no contexto administrativo e compõem o campo mais amplo dos estudos e das teorias organizacionais. A dinâmica organizacional evidenciou a importância das decisões no contexto administrativo, fato apontado por Barnard (1938) e Simon (1972). Mintzberg (1973), em seu texto sobre a natureza do trabalho gerencial, afirmou que os administradores dedicam grande parte do tempo ao processo decisório.

Outro motivo para se estudar o processo decisório diz respeito à sua natureza intrínseca, uma vez que ele está relacionado à alocação de recursos escassos e ao exercício do poder nas organizações, especialmente no caso de decisões que acarretem consequências para as organizações. Assim, torna-se de vital interesse para os atores ou grupos de interesse.

Além disso, são pontos centrais desse estudo as questões referentes a quem está envolvido na decisão, quem é omitido ou deixado de fora, quem está em posição de exercer influência ou quem pode incluir ou retirar itens da agenda, uma vez que essas questões são cruciais para compreender como e por que as organizações são o que são e como foram conduzidas até esse estágio.

Uma questão relevante no processo decisório passa por entender como, por vezes, as mesmas estruturas e estratégias similares e que representam um grupo de atores com interesses afins e possíveis atingem resultados distintos. Assim, a forma organizacional representa um meio para categorizar os agentes subordinados, ou ao menos afetados, pelo quadro institucional (INGRAM, 1998, p. 268-269).

DiMaggio (1998) argumenta que a mudança institucional frequentemente necessita de coalizões de atores com base em seus interesses e requer que eles participem de uma mesma rede social ou campo. A construção dessas coalizões é facilitada pela habilidade que os atores têm em explicitar seus interesses como altruístas e pela consistência desses com os valores básicos daquela sociedade (INGRAM, 2001, p. 270). 
Callon e Law (1982) exemplificam essa demonstração com o uso de argumento do tipo "é interesse nosso...", permitindo definir a posição do ator em relação ao outro, e propõem o seguinte processo para a transmissão de interesses entre atores sociais:

1. Em alguma medida, os interesses são articulados e explorados em termos da escolha entre cursos de ação e limitados pelas instituições e, consequentemente, por sua participação na rede social.

2. Os atores têm uma concepção idiossincrática dos seus interesses.

3. O valor relativo dessas escolhas é, em parte, determinado pela exploração e imputação de interesse a outros atores.

4. Uma exploração mais aprofundada baseia-se em indicadores relacionados aos interesses alheios.

5. Esse processo é mutuamente interdependente.

Nesse processo, os atores criam mapas de interesses, os quais são atribuídos aos demais de forma relativamente estável, sendo que uma revisão desse mapa só é possível quando informações sociais relevantes para aquela situação são apropriadas por meio de um processo reflexivo, no qual os interesses próprios, dos outros e mútuos podem ser alterados. Essa transmissão de interesses é efetivada pelo engajamento de terceiros por meio de um dispositivo comunicativo.

Assim, o engajamento se dá por meio de processos sociais, e sua relevância para este trabalho se deve ao fato de que ele permite impor uma determinada ordem às relações sociais, definindo e reforçando instituições, grupos e organizações. Nesse contexto, as instituições são histórica e socialmente construídas pela interação entre atores com base em expectativas e interpretações do comportamento de outros, fazendo com que o fato estilizado, que emerge desse processo, adquira status de premissa moral e ontológica.

Há interesse continuado neste campo há meio século. Extensos trabalhos de revisão e sistematização dos estudos anteriores foram realizados, mais recentemente, por Elbana (2006). Entre as metodologias empregadas para geração de teorias, estavam a observação, os levantamentos, a experimentação em laboratório, a simulação, os estudos de caso único ou múltiplos, as narrativas e a análise de discurso.

Os estudos no campo da Tomada de Decisão Organizacional podem contribuir para o setor público, na medida em que muitas de suas lentes teóricas permitem olhar adiante, em suas diversas correntes, e melhor compreender comportamentos ou escolhas num gradiente que vai de apenas uma ferramenta para resolução de um problema bem definido, até uma situação complexa de disputa pelo poder, na 
qual problemas são pouco estruturados, sendo possível segmentá-los em duas correntes: uma que dá primazia aos aspectos políticos na decisão e a outra que não dá (ELBANNA, 2006).

O reconhecimento do mecanismo de engajamento institucional, combinado às teorias do processo decisório, pode trazer nova perspectiva, visando a melhor compreender processos sociais complexos no nível das políticas públicas e de seus arranjos organizacionais, reconhecendo formalmente aspectos políticos cruciais às políticas públicas e administrativas do setor público, e esse é exatamente o motivo pelo qual o processo decisório é um desafio que se renova para nossa gestão pública no século 21 .

\section{Conclusão}

Observamos que ideias centrais do movimento da NGP continuam a se desenvolver, seja como instrumento analítico, seja como ferramenta ou mesmo como corpo de ideias. Ainda é necessário avançar na discussão e contribuir para o desenvolvimento dos pontos aqui propostos. Como dito anteriormente, não se trata de uma agenda fácil, pois depende de vontade política e, consequentemente, direcionamento de recursos humanos e financeiros. No campo da pesquisa em administração pública, observam-se diversas iniciativas e redes de pesquisa transnacionais atuando nos temas aqui discutidos.

Em relação à promoção de um governo aberto, discutiu-se a importância de que práticas pontuais confiram espaço a uma política de Estado que o promova, garantindo transparência, participação e accountability, com o amplo apoio de TICs.

Quanto ao combate à corrupção, trata-se também de um grande desafio, não apenas pela nocividade que causa, mas, principalmente, pela necessidade de entender a corrupção institucional como sendo algo a ser também amplamente combatido e que possui efeitos tão prejudiciais como a corrupção individual.

No que diz respeito às parcerias entre Estado e organizações privadas, discutiuse a necessidade de que o desenho institucional das parcerias esteja embasado nas normas sociais subjacentes aos modos de interação entre atores estatais e privados.

Numa sociedade mediada intensamente pela tecnologia da informação e das comunicações, é possível antever que a análise das demandas dos cidadãos, com emprego de técnicas desenvolvidas para lidar com a big data, permitiu que os cidadãos auxiliem na provisão de serviços e na identificação de novos serviços a serem oferecidos à população. Nesse ponto, a sociedade paciente que recebe a provisão de serviços dá vez à sociedade ativa que recebe e cocria serviços. 
Quanto à proposta de compartilhamento de serviços, é importante frisar que a mesma não envolve a centralização das competências, e sim a busca da maneira mais eficiente de realizar atividades em processos passíveis de padronização. Porém, um alerta deve ser dado: ao focalizar com forte ênfase os objetivos e incentivos no sentido da redução de custos, tais soluções podem se demonstrar disfuncionais quando em ambiente característico como o setor público, no qual os objetivos são ambíguos e de definição fluida (BEVAN; HOOD, 2006).

A compreensão das escolhas realizadas no âmbito das organizações públicas permanece um desafio para a gestão pública contemporânea, seja pelo seu efeito histórico, pela sua complexidade, pela diversidade de referências ou mesmo pela dificuldade em se reconhecer e aceitar formalmente que algumas escolhas serão permeadas por outras, nem sempre adequadas quando vistas de perspectivas políticas ou administrativas diferentes, ou mesmo opostas em relação ao setor público e ao seu papel na sociedade.

Neste texto, apontamos para esses seis desafios da Gestão Pública no século 21. A intenção é colaborar com essas ideias para fomentar futuras discussões no campo, contribuindo, assim, para seu aprofundamento e desenvolvimento em várias direções.

\section{Referências bibliográficas}

Abrucio, F. L.; Loureiro, M. R. Finanças Públicas, Democracia e Accountability. In: Arvate, P. R.; Biderman, C. (Orgs.). Economia do Setor Público no Brasil. Rio de Janeiro: Elsevier Campus, 2004.

Angelico, F. Lei de Acesso à Informação. São Paulo: Estúdio Editores, 2015.

ARSENAULt, J. Forging Nonprofit Alliances. San Francisco: Jossey-Bass Publishers, 1998.

AVRITZER, L. Democracy and the public space in Latin America. Princeton: Princeton University Press, 2002.

Avritzer, L.; Navarro, Z. (Orgs.). A inovação democrática no Brasil. São Paulo: Cortez, 2003.

AVRITZER, L. (Org.). Experiências nacionais de participação social. Minas Gerais: UFMG; São Paulo: Cortez, 2009. BARNARD, C. The Functions of the Executive. Harvard: Harvard University Press, 1938.

BERGERON, B. Essentials of Shared Services. Hoboken, NJ:Wiley, 2003.

BEVAN, G.; HOOD, C. What's measured is what matters: Targets and gaming in the English public health care system. Public Administration, v. 84, n. 3, p. 517-538, 2006.

CALLON, M.; LAW, J. On interests and their transformation: enrolment and counterenrolment. Social Studies of Science, v. 12, n.4, p. 612-25, 1982. 
Cunha, M. A. V. C; Coelho, T. R; Pozzebon, M. Internet e Participação: O caso do orçamento participativo digital de Belo Horizonte. Revista de Administração de Empresas, v. 54, n. 3, p. 296-308, 2014.

CUnha, M. A. V. C; MiRAndA, P. R. M. Uso de TIC pelos governos: uma proposta de agenda de pesquisa a partir da produção acadêmica e da prática nacional. Revista Organização \& Sociedade, v. 20, n. 66, p. 543-566, 2013.

DAGNINO, E. Civil society in Latin America. In: EDWARDS, M. (Ed.). The Oxford handbook of civil society. New York: Oxford University Press, p.122-133, 2011.

Terra, 2002.

(Org.). Sociedade civil e espaços públicos no Brasil. São Paulo: Paz e

DAgnino, E; TAtAgIBA, L. (Orgs.). Democracia, sociedade civil e participação. Chapecó: Argos, 2007.

Dehoog, R. H.; Salamon, L. M. Purchase-of-Service Contracting. In: SAlamon, L. M. (Ed.). The Tools of Government: a guide to the new Governance. Oxford: Oxford University Press, 2002

DimAgGIO, P.J. Interest and agency in institutional theory. In: Zucker, L.G. (ed.). Institutional Patterns and Organizations. Cambridge: Ballinger, 1998.

Dunleavy, P; MARgetTs $H$. The second wave of digital-era governance: A quasiparadigm for government on the Web. Philosophical Transactions of the Royal Society A, v. 371, p. 1-17, 2013.

ELBANNA, S. Strategic decisionmaking: process perspectives. International Journal of Management Reviews, v. 8, n. 1, p. 1-20, 2006.

ELSTER, J. Deliberative democracy. Cambridge: Cambridge University Press, 1998.

FEnWICK, T; MANGEZ, E; OzGA J. (eds). Governing Knowledge: comparison, knowledge-based technologies and expertise in the regulation of education. London: Routledge, 2014.

Fugini, M. G; Maggiolini, P; Pagamicı, B. Por que é difícil fazer o verdadeiro "governo eletrônico". Revista Produção, v. 15, n. 3, p. 300-309, 2005.

Glendinning, C., MeAns, R. Rearranging the deckchairs on the Titanic of long-term care - is organisational integration the answer? Critical Social Policy, v. 24, n. 4, p. 435-457, 2004.

GREK S; OzGA J. Re-inventing public education: the new role of knowledge in education policy making. Public Policy and Administration v. 25, n. 3, p. 271-288, 2010.

INGRAM, P. Changing the rules: interests, organizations, and institutional change in the U.S. Hospitality Industry. In: Brinton, M.C.; Nee, V. The new institutionalism in sociology. Stanford, CA: Stanford University Press, 2001.

LAVAlle, A. G. Após a participação: nota introdutória. Lua Nova, São Paulo, v. 84, p.13-23, 2011.

Lavalle, A.; Houtzager, P. P.; CAStello, G. Democracia, pluralização da representação e sociedade civil. Lua Nova, v. 67, p. 49-103, 2006. 
LESSIG, L. Institutional Corruptions. Edmond J Safra Working Papers n. 1, 2013. Disponível em: < http://papers.ssrn.com/sol3/papers.cfm?abstract_id=2233582>. Acesso: em 15 maio 2015.

LeSsIG, L. Republic, Lost. How Money Corrupts Congress and a Plan to Stop it. New York: Twelve Hachette Book Group, 2011.

LEUTZ, W. Five Laws for Integrating Medical and Social Services: lessons from the United States and the United Kingdom. The Milbank Quarterly, v. 77. n. 1, p. 77-110, 1999.

LÜCHMANN, L. H. H. A representação no interior das experiências de participação. Lua Nova, v. 70, p. 139-170, 2007.

MAIA, M., DINIZ, E. O conceito de Esfera Pública Interconectada e o site Webcidadania no Brasil. Gestão \& Regionalidade, v. 29, p. 97-111, 2012.

MARgetTS, H. Dunleavy, P. The second wave of digital-era governance: a quasiparadigm for government on the Web. Phil Trans R Soc A371:20120382. 2013. HTTP://DX.DOI.ORG/10.1098/RSTA.2012.0382

MASHAW, Jerry. Accountability and institutional design: some thoughts on the grammar of governance. In: DoWDLE, Michael. Public Accountability: Designs, Dilemmas and Experiences. Cambridge University Press, 2006.

MCIVOR, R; MCCRACKEN, M; MCHUGH, M. Creating outsourced shared services arrangements: Lessons from the public sector. European Management Journal, v. 29, n. 6, p. 448-461, 2011.

MeIJer A. Co-production in an information age: individual and community engagement supported by new media. Voluntas, v. 23, n. 4, p. 1156-1172, 2012.

Menezes, A. M. F; FonseCA, M. J. M. Governo eletrônico: um novo caminho para a administração pública? Bahia Análise e Dados, vol. 15, n. 2-3, p. 333-341, 2005.

MinTZBERG, H. The nature of managerial work. Harper e Row: Nova York, 1973.

NAJAM, A. The Four-C's of third sector-government relations: cooperation, confrontation, complementarity, and co-optation, Nonprofit Management and Leadership, v. 10, n. 4, p. 375-396, 2000.

NoBRE, M. Participação e deliberação na teoria democrática: uma introdução. In: Coelho, V. S. P; NoBre, M (orgs.). Participação e deliberação: teoria democrática e experiências institucionais no Brasil contemporâneo. São Paulo: Editora 34, 2004.

NOVECK, B. S. Wiki government: how technology can make government better, democracy stronger, and citizens more powerful, Washington, D.C: Brookings Institution Press, 2009

OPEn Government PARTNERShIP. Disponível em: <http://www.opengovpartnership. org>. Acesso em: 29 mai. 2015.

PAteman, Carole. Participation and democratic theory. London: Cambridge University Press, 1970.

PINHO, J. A. G. Sociedade da informação, capitalismo e sociedade civil: reflexões sobre política, internet e democracia na realidade brasileira, Revista de Administração de Empresas, v. 51, n. 1, p. 98-106, 2011. 
PozzeBon, M. The implementation of configurablet Technologies: negotiations between global principles and local contexts. Doctoral dissertation, McGill University, Montreal, Quebec, Canadá, 2003.

ROSE-ACKERMAN, S. Corruption and Government: causes, consequences and reform. Cambridge: Cambridge University Press, 2007.

SALINAS, N. S. C. Modelos de controle das parcerias entre Estado e entidades do terceiro setor e desenho institucional das políticas públicas. Revista de Direito do Terceiro Setor, Belo Horizonte, v. 14, n. 2, p. 9-28, 2013.

SALINAS, N. S. C. Reforma Administrativa de 1967: a reconciliação do legal com o real. In: MotA, C. G; SAlinAS, N. S. C. (Orgs). Os juristas na formação do EstadoNação brasileiro: de 1930 aos dias atuais. São Paulo: Saraiva, p. 453-482, 2010.

SAMPAIO, R. C.; MAIA, R. C. M, MARQUES, F. P. J. Participação e deliberação na internet: um estudo de caso do orçamento participativo digital de Belo Horizonte. Opinião Pública, Campinas, v. 16, n. 2, p. 466-477, 2010.

SANCHEZ, F. R. O orçamento participativo em São Paulo (2001/2004): uma inovação democrática. In: AVRITZER, L. (Org.). A participação em São Paulo. São Paulo: Editora Unesp, 2004.

SANTOS, L. G. In: SAVAZONI, R; Cohn, S. (orgs). Cultura digital.br. Rio de Janeiro: Beco do Azougue, 2009.

SCLAIR, El. D. You don't always get what you pay for: the economics of privatization. The Century Foundation, 2001.

Simon, H.A. Comportamento administrativo: estudo dos processos decisórios nas organizações administrativas. Rio de Janeiro: FGV, 1972.

TATAGIBA, L. A institucionalização da participação: os conselhos municipais de políticas públicas na cidade de São Paulo. In: AVRITZER, L. (Org.). A participação em São Paulo. São Paulo: Editora da Unesp, p. 323-370, 2004.

Os Conselhos Gestores e a democratização das políticas públicas no Brasil. In: DAgnino, E. (Org.). Sociedade civil e espaços públicos no Brasil. São Paulo: Paz e Terra, 2002.

TEIXEIRA, E. C. Conselhos de políticas públicas: efetivamente uma nova institucionalidade participativa? In: CARvalho, M. C. A. A.; TelXeIRA, A. C. C. (Org.). Conselhos gestores de políticas públicas. São Paulo: Pólis, p. 97-120, 2000.

THOMPSON, DENNIS F. Ethics in Congress: from individual to institutional corruption. The Brookings Institution, 1995.

WALDFOgEL, J. The New Wave of Service Integration. Social Service Review, v. 71, n. 3, p. 463-484, 1997.

WALSh, P; Mcgregor-LoWndes, M; NeWton, C. Shared Services: lessons from the public and private sectors for the nonprofit sector. CPNS Working Paper n. 34. Brisbane: QLD, 2006.

WAMPLER, B. Participatory budgeting in Brazil. Pennsylvania: The Pennsylvania State University Press, 2007. 
WILIAMSON, B. Knowing public services: cross-sector intermediaries and algorithmic governance in public sector reform. Public Policy and Administration, v. 29, n. 4, 2014, p. 292-312.

YIN, Robert K. Estudo de caso: planejamento e métodos. São Paulo: Artemed, 2005. YONG, DENNIS R. YONG. Complementary, Supplementary, or Adversarial? A Theoretical and Historical Examination of Nonprofit-Government Relations in the United States. In: BorIS, Elizabeth T.; STEUERLE, C. Eugene (Ed.). Nonprofits and Government: Collaboration \& Conflict. 2.ed. Washington: The Urban Institute Press, 2006.

YoUNG, IRIS M. Representação política, identidade e minorias. Lua Nova, São Paulo, v. 67 , p. 139-190, 2006.

Ricardo Luiz Pereira Bueno

Possui Doutorado em Administração pela Universidade Federal do Rio Grande do Sul (UFRGS). Atualmente é Professor Adjunto da Universidade Federal de São Paulo (Unifesp).

Contato: ricardolpbueno@gmail.com

Gabriela de Brelàz

Possui Doutorado em Administração Pública e Governo pela Fundação Getúlio Vargas de São Paulo. É Professora Adjunta da Universidade Federal de São Paulo (Unifesp) na Escola Paulista de Política, Economia e Negócios.

Contato: gabriela.brelaz@unifesp.br

Natasha Schmitt Caccia Salinas

Natasha é Doutora em Direito pela USP. É Professora Adjunta da Universidade Federal de São Paulo (Unifesp), lotada junto à Escola de Economia, Política e Negócios, campus de Osasco.

Contato: natasha.salinas@unifesp.br 